\title{
Increase in Intracellular Calcium Concentration Induced Differentiation of Hematopoietic Stem Cells
}

\author{
Aditi Singh ${ }^{1}$, Elcim Eroglulari ${ }^{1}$, Athar Aziz ${ }^{2}$ \\ ${ }^{1}$ Laboratory of Translational Medicine, University of Salford, Manchester, UK \\ ${ }^{2}$ Department of Biomedical Sciences, University of Salford, Manchester, UK
}

Email address:

a.singh6@edu.salford.ac.uk (A. Singh), e.eroglulari@edu.salford.ac.uk (E. Eroglulari), A.aziz@salford.ac.uk (A. Aziz)

To cite this article:

Aditi Singh, Elcim Eroglulari, Athar Aziz. Increase in Intracellular Calcium Concentration Induced Differentiation of Hematopoietic Stem Cells. International Journal of Immunology. Vol. 8, No. 2, 2020, pp. 18-24. doi: 10.11648/j.iji.20200802.12

Received: July 24, 2019; Accepted: May 2, 2020; Published: June 3, 2020

\begin{abstract}
Calcium $\left(\mathrm{Ca}^{2+}\right)$ is a key secondary messenger. It is responsible for the generation of intracellular signals which regulates the cellular division, differentiation and cell death. Intracellular calcium concentration $\left(\left[\mathrm{Ca}^{2+}\right]_{\mathrm{i}}\right)$ is maintained at a $10^{5}$-fold lower level than the extracellular calcium concentration. The rise in $\left[\mathrm{Ca}^{2+}\right]_{\mathrm{i}}$ induces differentiation in stem cells and this increased $\left[\mathrm{Ca}^{2+}\right]_{\mathrm{i}}$ also serves as an early indicator of cellular death by apoptosis. In haematological malignancies such as chronic myeloid leukaemia $(\mathrm{CML})$, the cells are arrested in the megakaryocytic stage and are unable to differentiate into platelets. In this study, we treated two cell lines derived from CML patients-K562 and Marimo, with Ca ${ }^{2+}$ channel blockers (CCBs) - fendiline and BTP2. We examined the effects of CCBs on cellular differentiation and growth in the two cell lines. The $\left[\mathrm{Ca}^{2+}\right]_{\mathrm{i}}$ was found to increase with the increasing concentration of the CCBs. The morphology of the cells was then examined under a light microscope. It was observed that this increasing $\left[\mathrm{Ca}^{2+}\right]_{\mathrm{i}}$ subsequently induced differentiation in both the cell lines. Differentiation is closely linked with proliferation. At even higher concentrations $(25 \mu \mathrm{M})$, it was observed that these CCBs led to a decline in the number of cells. Cell cycle analysis was then performed to verify if the CCBs had an apoptotic effect on the cell lines. On performing cell cycle analysis, it was concluded that these CCBs at a higher concentration triggered apoptosis in the cells. The results suggest that CCBs causes increase in the intracellular calcium concentration in the cell lines which leads to differentiation of the hematopoietic stem cells. In addition to this, these CCBs are toxic for the cells at high concentrations as they induce apoptosis in the cell lines.
\end{abstract}

Keywords: Calcium, Differentiation, Chronic Myeloid Leukaemia

\section{Introduction}

$\mathrm{Ca}^{2+}$ is an enormously versatile molecule. $\mathrm{Ca}^{2+}$, a secondary messenger, generates signals intracellularly for regulation of cellular processes like apoptosis, cell proliferation and differentiation [1]. The underlying versatility of $\mathrm{Ca}^{2+}$ signalling mechanisms with respect to spatiotemporal patterning, amplitude and speed is responsible for regulating so many cellular processes [2]. Despite the importance of calcium in regulating vital cellular processes, this research has gained interest very recently [3]. $\mathrm{Ca}^{2+}$ concentration is maintained at a 20,000-100,000-fold lower concentration in the cytosol than the extracellular spaces. $\mathrm{Ca}^{2+}$ is pumped out of the cytosol to the endoplasmic reticulum (ER), extracellular spaces and mitochondria to maintain the low levels [4].
The rise in $\mathrm{Ca}^{2+}$ concentration initiates phosphoinositide metabolism which is crucial in the differentiation process [5]. The principal enzyme involved in this process is phospholipase C (PLC). It is responsible for hydrolysis of phosphatidylinositol bisphosphate $\left(\mathrm{PIP}_{2}\right)$ into diacylglycerol (DAG) and inositol trisphosphate $\left(\mathrm{IP}_{3}\right)$. Intracellular $\mathrm{Ca}^{2+}$ stores regulated by inositol 1,4,5-triphosphate receptors $\left(\mathrm{IP}_{3} \mathrm{Rs}\right)$ are present inside the cells. $\mathrm{IP}_{3} \mathrm{Rs}$ are susceptible to signals from platelet-derived growth factor, histamine and ATP. They rely on store-operated channel entry (SOCE) for $\mathrm{Ca}^{2+}$ uptake and filling the intracellular stores of $\mathrm{Ca}^{2+}[6]$. $\mathrm{PLC}$ is also a requirement for activation of store-operated channels which restores $\mathrm{Ca}^{2+}$ in intracellular stores. $\mathrm{Ca}^{2+}$ release from the intracellular stores is stimulated by DAG and $\mathrm{IP}_{3}$ which consequently activates protein kinase $\mathrm{C}(\mathrm{PKC})$. The sustained rise in $\left[\mathrm{Ca}^{2+}\right]_{\mathrm{i}}$ along with transcription factors 
regulated by $\mathrm{PKC}$, increases the transcription of genes responsible for differentiation. Additionally, the $\mathrm{Ca}^{2+}$ receptors make a complex with Golgi $\mathrm{Ca}^{2+}$ pump and $\mathrm{IP}_{3}$ receptors and control the release and uptake of $\mathrm{Ca}^{2+}$ from intracellular stores [7, 8].

A substantial increase in the concentration of cytosolic $\mathrm{Ca}^{2+}$ triggers apoptosis [9]. The apoptosis can then occur through two pathways-mitochondrial and ER-mediated pathways [10]. Intracellular $\mathrm{Ca}^{2+}$ stores regulated by Inositol 1,4,5-triphosphate receptors $\left(\mathrm{IP}_{3} \mathrm{Rs}\right)$ are present inside the cells. $\mathrm{IP}_{3} \mathrm{Rs}$ are susceptible to signals from a platelet-derived growth factor, histamine and ATP. They rely on storeoperated channel entry for $\mathrm{Ca}^{2+}$ uptake and filling the intracellular stores of $\mathrm{Ca}^{2+}[6]$.

Several tumour suppressor genes and oncogenes affect the functioning of $\mathrm{IP}_{3} \mathrm{Rs}$ and disrupt their capability to regulate mitochondrial $\mathrm{Ca}^{2+}$ influx. Thus, an increase in $\mathrm{Ca}^{2+}$ in the cytosol is an initial indication of apoptosis [11]. In the ER, foldases and chaperones are present on the surface which mediates around $30 \%$ of the protein folding and maturation. $\mathrm{Ca}^{2+}$ is required as a cofactor for the ideal functioning of chaperones [12]. $\mathrm{Ca}^{2+}$ depletion from ER alters protein folding processes and causes a condition of stress in the ER which initiates unfolded protein response (UPR) [13]. If the UPR is not able to restore the homeostasis in the cell, it alters its signalling and initiates cell death via apoptosis [14].

In this study, we used two CCBs- Fendiline and BTP2. Even at a very low concentration, fendiline has been shown to be an extremely effective CCB [15]. It binds with Sarco/endoplasmic reticulum calcium ATPase (SERCA) receptor and inhibits $\mathrm{Ca}^{2+}$ uptake by ER. BTP2 is a pyrazole derivative and it directly blocks the $\mathrm{Ca}^{2+}$ uptake by SOCE [16]. The effects of these CCBs were tested on two cell linesK562 and Marimo. The cells were treated with different concentrations of CCBs and their effect on the $\left[\mathrm{Ca}^{2+}\right]_{\mathrm{i}}$ and differentiation of the cells were analysed. Also, cell cycle analysis was performed.

\section{Method}

Marimo (having CALR mutation) and K562 (having BCRABL genes) cell lines cultured in GIBCO $\left({ }^{\circ}\right.$ RPMI 1640 medium were used for the experiments. Medium $(440 \mathrm{ml})$ was supplemented with fetal bovine serum (50ml), streptomycin/penicillin $(5 \mathrm{ml})$ and L-glutamine $(5 \mathrm{ml})$. Splitting of cells was carried in aseptic conditions every 2-3 days. Cells were transferred in a test tube and centrifuged (1200 rpm, 5 mins). After discarding the supernatant, medium ( $1 \mathrm{ml})$ was added in tubes with K562 cells and medium $(3 \mathrm{ml})$ was added in tubes with Marimo cells and mixed thoroughly. One-fourth of the medium containing cells were then transferred in two separate $\mathrm{T} 75$ flasks containing medium $(10 \mathrm{ml})$ and incubated at $37^{\circ} \mathrm{C}$ in a $\mathrm{CO}_{2}$ incubator. The flasks were examined, before and after splitting, under a microscope for any contamination.

\subsection{Treatment of Marimo and $\mathrm{K} 562$ for $\left[\mathrm{Ca}^{2+}\right]_{i}$ Analysis}

The cells were collected in two tubes by centrifugation after splitting for 24 hours. Medium $(12 \mathrm{ml})$ was added to each tube containing the cell lines and mixed thoroughly. Cells $(1 \mathrm{ml})$ was added to 24-well plate along with different concentrations of CCBs $(0,5$ and $25 \mu \mathrm{M}$ of BTP2 and fendiline) and incubated for a day. Cells were then collected in centrifuge tubes and centrifuged $(1500 \mathrm{rpm}, 5$ mins). After discarding the supernatant, $1 \mathrm{X}$ phosphate buffer saline (PBS) $(500 \mu 1)$ was added to each tube. Fluo8 ® $(50 \mu \mathrm{l})$ was mixed with $1 \mathrm{X}$ PBS $(2.5 \mathrm{ml})$ and $100 \mu \mathrm{l}$ of this mixture was mixed in each tube and tubes were incubated $\left(30 \mathrm{mins}, 37^{\circ} \mathrm{C}\right)$. FACSVerse BD ${ }^{\circledR}$ was used for analysis of $\left[\mathrm{Ca}^{2+}\right]_{\mathrm{i}}$.

\subsection{Treatment of Marimo and K562 for Cell Cycle Analysis}

The cells were collected in two tubes by centrifugation after splitting for 24 hours. Medium $(25 \mathrm{ml})$ was added to each tube containing the cell lines and mixed thoroughly. Cells $(1 \mathrm{ml})$ was added to 24-well plate along with different concentrations of CCBs $(0,1,5$ and $25 \mu \mathrm{M}$ of BTP2 and fendiline) and incubated for a day. Cells were then collected in centrifuge tubes and centrifuged (8000rpm, 3 mins). Ethanol $(70 \%)$ was added to the tubes after discarding the supernatant and tubes were incubated on ice (15 mins). $1 \mathrm{X}$ PBS $(500 \mu 1)$ was added and tubes were centrifuged (8000 rpm, 3 mins). PBS $(100 \mathrm{ml})$ was added upon discarding the supernatant. RNase $(100 \mu \mathrm{l})$ was mixed with PBS $(10 \mathrm{ml})$ and $100 \mu \mathrm{l}$ of this mixture was added in each tube and incubated for 10 mins. PBS $(100 \mu l)$ was added to each tube and centrifuged (8000rpm, 3 mins). Propidium Iodide $(100 \mu \mathrm{l})$ was then mixed in each tube. Cell cycle analysis was then done using FACSVerse BD ${ }^{\circledR}$ machine.

\subsection{Treatment of Marimo and K562 Cells for Microscopy}

The cells were collected in two tubes by centrifugation after splitting for 24 hours. Medium $(24 \mathrm{ml})$ was added to each tube containing the cell lines and mixed thoroughly. Cover slips were placed in each well of a 12-well plate and collagenase $(2 \mathrm{ml})$ was added to each well and discarded after 15 mins. Cells $(2 \mathrm{ml})$ was added to 12 -well plate along with different concentrations of CCBs $(0,5$ and $25 \mu \mathrm{M}$ of BTP2 and fendiline) and phorbol 12-myristate 13-acetate (PMA) $(1 \mu \mathrm{M})$ and incubated for 48 hours. Medium was removed after incubation and fixative $(2 \mathrm{ml})$ was added and incubated for 5 mins. Giemsa stain $(2 \mathrm{ml})$ and 1X PBS $(38 \mathrm{ml})$ was mixed and this mixture $(2 \mathrm{ml})$ was added to each well and incubated for 40 mins. Cover slips were washed under tap water and left to air dry until no visible residue was seen on cover slips. DBX was added to this cover slips and fixed on glass slides. The slides were observed under $40 \mathrm{X}$ magnification of a Leica light microscope (Leica, Heidelberg, Germany) for changes in the morphology and images were acquired using Leica air app. 


\section{Results}

\subsection{Higher Concentrations of Fendiline and BTP2 Results in Rise of Intracellular Calcium Concentrations}

FACSVerse ${ }^{\circledR}$ was used to measure the $\left[\mathrm{Ca}^{2+}\right]_{i}$ upon treating the cell lines with varying concentrations of CCBsFendiline and BTP2 $(5 \mu \mathrm{M}$ and $25 \mu \mathrm{M})$. The fluorescence indicator Fluo-8 was used which is known to emit green fluorescence upon binding with the free intracellular $\mathrm{Ca}^{2+}$ of the cell. This fluorescence is detected in the green fluorescent protein (GFP) channel in a FACS machine. The size of the cell is measured by forward scatter and granularity is determined by side scatter. Geometric mean of the fluorescence intensity of the FITC/GFP channel reflected the $\left[\mathrm{Ca}^{2+}\right]_{\mathrm{i}}$. The change in the fluorescence intensity from untreated to treated cells were analysed and $\mathrm{Ca}^{2+}$ concentrations along with various concentrations of BTP2 and fendiline are summarised in table 1. A graphical representation of this data was done (Figure 1). It was observed that for Marimo cell line, the $\left[\mathrm{Ca}^{2+}\right]_{\mathrm{i}}$ increased at 5 $\mu \mathrm{M}$ concentrations and then decreased at $25 \mu \mathrm{M}$ concentrations for both BTP2 and fendiline. In K562 cell line, an increase in intracellular $\mathrm{Ca}^{2+}$ was observed at both $5 \mu \mathrm{M}$ and $25 \mu \mathrm{M}$ concentrations of BTP2 and fendiline. This change was not very significant despite the increase in $\left[\mathrm{Ca}^{2+}\right]_{\mathrm{i}}$.

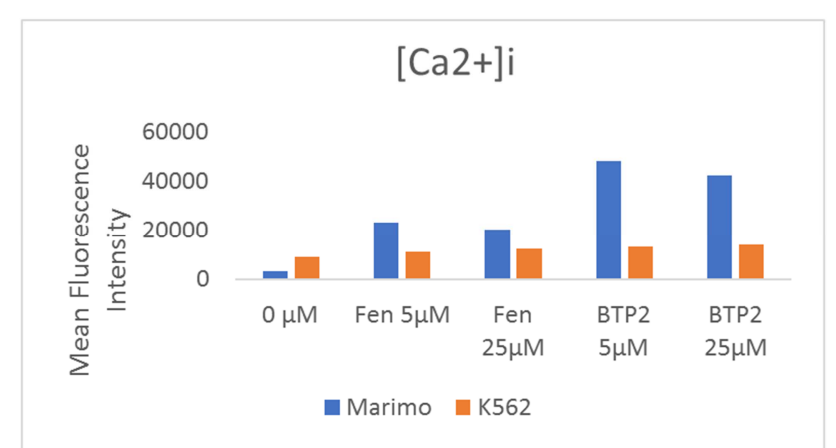

Figure 1. Increase in the $\left[\mathrm{Ca}^{2+}\right]_{i}$ as seen from FACS analysis. Various concentrations of CCBs used are represented on $x$-axis and the $y$-axis represents mean fluorescence intensity which is indicative of the $\left[\mathrm{Ca}^{2+}\right]_{i}$. Marimo and K562 cells are shown in blue and orange colour respectively.

Table 1. Mean fluorescence intensity with varying concentrations of CCBs in the two cell lines.

\begin{tabular}{llllll}
\hline & $\mathbf{0} \boldsymbol{\mu M}$ & Fen $\mathbf{5} \boldsymbol{\mu M}$ & Fen 25 $\boldsymbol{\mu M}$ & BTP2 $\mathbf{\mu} \boldsymbol{\mu M}$ & BTP2 25 $\boldsymbol{\mu M}$ \\
\hline Marimo & 3428.33 & 23213.5 & 20200.5 & 48036.5 & 42408.75 \\
K562 & 9117.25 & 11203.5 & 12470 & 13254 & 14155 \\
\hline
\end{tabular}

\subsection{CCBs Induced Differentiation in Hematopoietic Stem Cells}

The consequences of treating the cells with CCBs on their ability to differentiate were examined. Microscope was used to examine the cellular morphology and determine the differentiation. Giemsa stain was used for staining after which the cells were examined under 40X magnification under a light microscope (Figures $2 \& 3$ ). Multi-nucleated and rather large cells known as megakaryocytes were viewed under the microscope. Multiple fields were taken into consideration and the number of megakaryocytic cells present in each field was expressed in percentage. Five and twenty-five $\mu \mathrm{M}$ concentrations of CCBs was used for treating the cells along with a positive control- Phorbol 12-myristate 13-acetate (PMA), which is a known inducer of differentiation. The percentage of megakaryocytes along with the varying concentrations of CCBs were summarised (Table 2). The data was quantified and expressed in the form of graph (Figure 4). With fendiline in Marimo cells, it was observed that the number of megakaryocytes was higher with increasing drug concentration. However, with BTP2 in both cell lines and fendiline in K562 cell line, it was observed that at $5 \mu \mathrm{M}$ concentration, the percentage of megakaryocytes declined but at $25 \mu \mathrm{M}$ concentration, the number increased. An increase in number of megakaryocytes was seen when cells were treated with PMA.

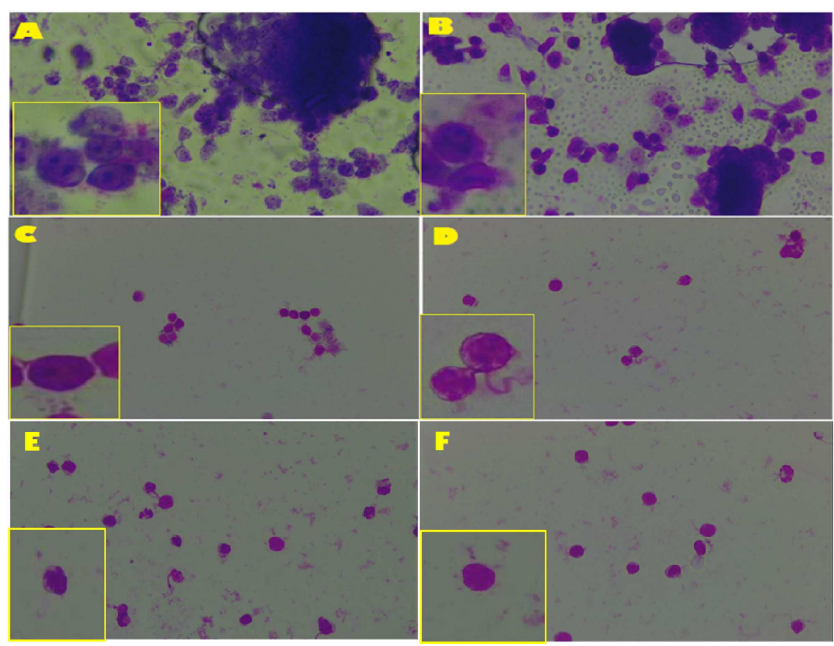

Figure 2. Differentiation induced by CCBs in the Marimo cell lines as seen under 40X magnification. Giemsa stain was used to stain the Marimo cells before analysing them under $40 X$ magnification of a light microscope. PMA induced differentiation is seen in Figure (A), the untreated cells are shown in Figure (B). Cells treated with $5 \mu \mathrm{M}$ and $25 \mu \mathrm{M}$ of fendiline are shown in Figure (C) and (D) respectively. Similarly, differentiation induced by $5 \mu M$ and $25 \mu M$ of BTP2 can be seen in Figure (E) and (F) respectively. A representation of the megakaryocytes which were being examined is shown in the small boxes present on each image. Leica Air software was used for image acquisition.

Table 2. The various concentrations of CCBs and PMA used along with the percentage of megakaryocytes are summarised below.

\begin{tabular}{lllllll}
\hline & PMA & Untreated & Fen $\mathbf{5} \boldsymbol{\mu M}$ & BTP2 5 $\boldsymbol{\mu M}$ & Fen 25 $\boldsymbol{\mu M}$ & BTP2 25 $\boldsymbol{\mu M}$ \\
\hline Marimo & 45.07 & 40.9 & 52.9 & 37.36 & 69.38 & 57.57 \\
K562 & 54.16 & 62.03 & 58.75 & 54.43 & 82.7 & 62.92 \\
\hline
\end{tabular}




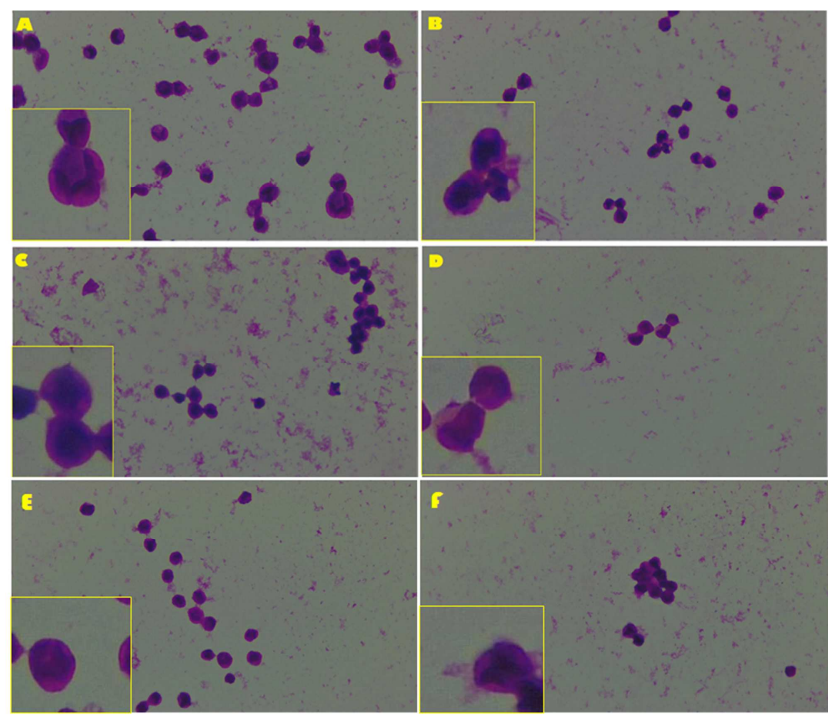

Figure 3. Differentiation induced by CCBs in the K562 cell lines as seen under 40X magnification. Giemsa stain was used to stain the K562 cells before analysing them under $40 X$ magnification of a light microscope. PMA induced differentiation is seen in Figure (A), the untreated cells are shown in Figure (B). Cells treated with $5 \mu M$ and $25 \mu M$ of fendiline are shown in Figure $(C)$ and $(D)$ respectively. Similarly, differentiation induced by $5 \mu M$ and $25 \mu M$ of BTP2 can be seen in Figure (E) and (F) respectively. A representation of the megakaryocytes which were being examined is shown in the small boxes present on each image. Leica Air software was used for image acquisition.

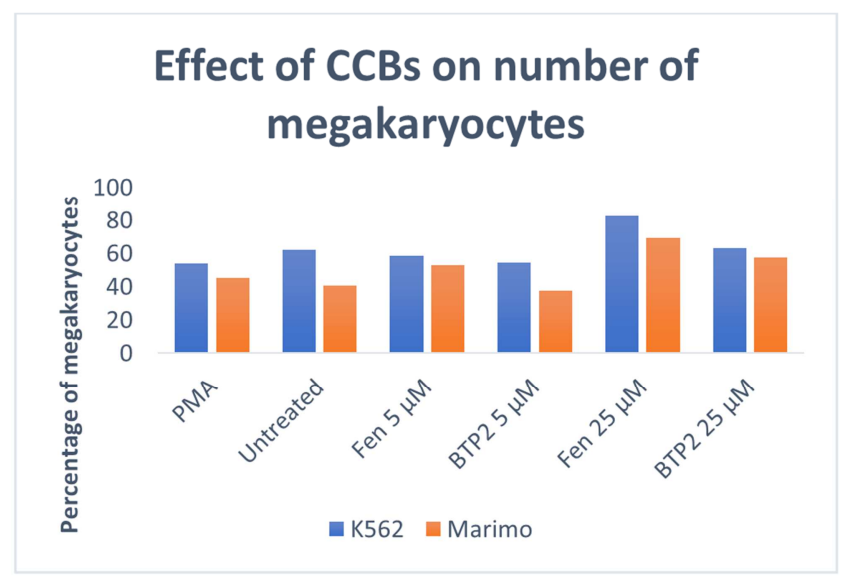

Figure 4. Effect of CCBs on the number of megakaryocytes. The $x$-axis of graph represents the varying concentration of the CCBs and positive control PMA and percentage of megakaryocytic cells are shown on y-axis. Blue colour represents the K562 cell lines whereas the Marimo cell lines are represented by orange colour.

\subsection{Higher Concentration of CCBs Are Toxic for K562 Cell Lines}

Proliferation and differentiation are closely related. While analysing the effects of $\mathrm{CCBs}$ on the cell lines, it was observed that cell number was declining. Cell cycle analysis was performed to determine if the cells were undergoing apoptosis. Propidium Iodide was used to stain the cells and cell cycle analysis was carried out in FACS machine. Dead cells take up the propidium iodide stain. The average percentage of parent population in each stage of the cell cycle like Sub-G1, G2/M, S and G1 phase was obtained by FACS. Varying concentrations of the CCBs along with average percentage of parent population is summarized (Table 3). A graph was made upon quantification of data (Figures 5 \& 6). The percent parent population in G1 phase increased with increasing concentrations of fendiline but decreased with increase in concentration of BTP2. A marked decrease in cell number was seen in $\mathrm{S}$ phase at $25 \mu \mathrm{M}$ concentration of both fendiline and BTP2. For G2/M phase, cell number decreased with increasing concentrations of CCBs. Cell number in SubG1 phase increased substantially with increasing concentrations of CCBs $(1-25 \mu \mathrm{M})$. It can be concluded that higher concentrations of CCBs $(25 \mu \mathrm{M})$ was toxic for cells as cells present in Sub-G1 phase are indicative of undergoing apoptosis.

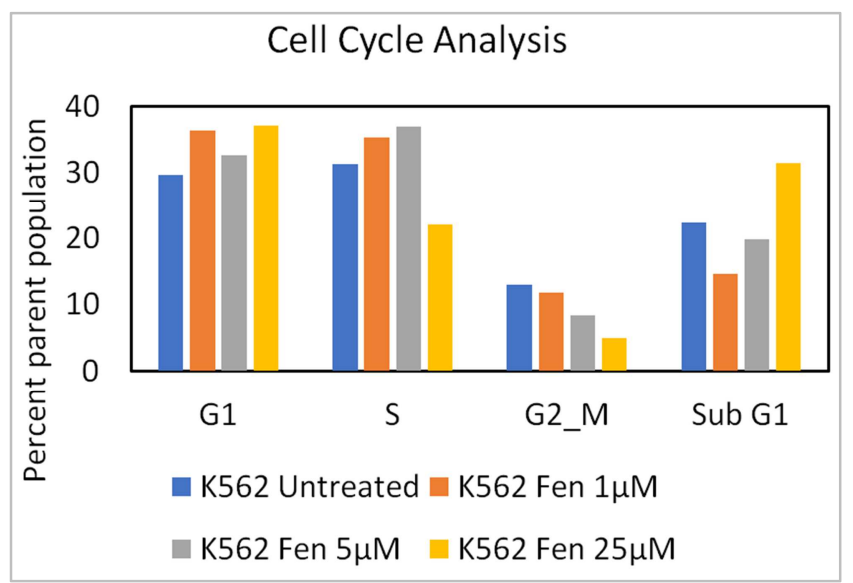

Figure 5. Depiction of percent parent population in each phase along with various concentration of BTP2. X-axis indicates the various phases of cell cycle. Y-axis indicates the percent parent population in each phase. Untreated cells are indicated by blue bar, orange, grey and yellow colour represents $1 \mu \mathrm{M}, 5 \mu \mathrm{M}$ and $25 \mu \mathrm{M}$ of BTP 2 respectively.

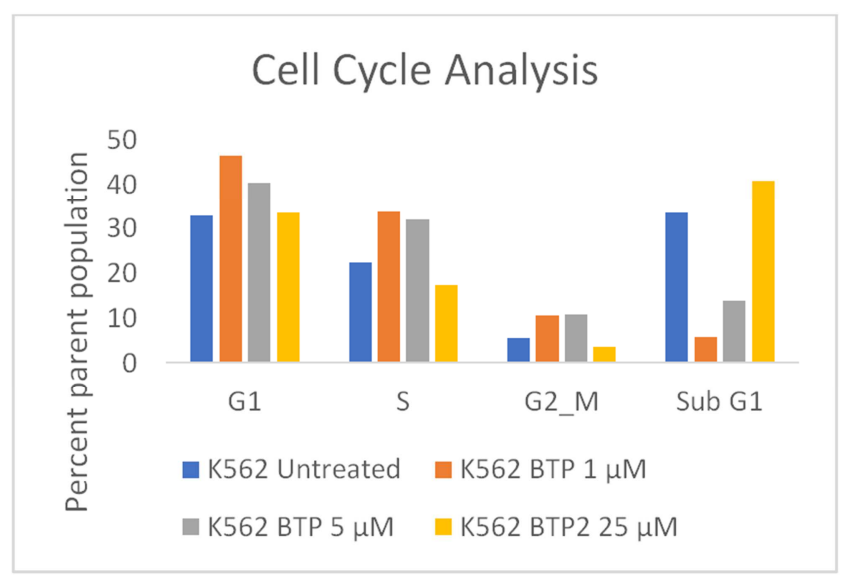

Figure 6. Depiction of percent parent population in each phase along with various concentration of BTP2. X-axis indicates the various phases of cell cycle. Y-axis indicates the percent parent population in each phase. Untreated cells are indicated by blue bar, orange, grey and yellow colour represents $1 \mu M, 5 \mu M$ and $25 \mu M$ of BTP 2 respectively. 
Table 3. Various concentrations of CCBs and the per cent parent population in different phases.

\begin{tabular}{lllll}
\hline & G1 & S & G2_M & Sub G1 \\
\hline K562 Untreated & 29.58 & 31.26 & 13.013 & 22.43 \\
K562 Fen $1 \mu \mathrm{M}$ & 36.30 & 35.26 & 11.74 & 14.68 \\
K562 Fen $5 \mu \mathrm{M}$ & 32.59 & 36.9 & 8.45 & 19.8 \\
K562 Fen $25 \mu \mathrm{M}$ & 37.03 & 22.05 & 4.91 & 31.4 \\
K562 BTP2 $1 \mu \mathrm{M}$ & 46.361 & 33.83 & 10.56 & 5.66 \\
K562 BTP2 $5 \mu \mathrm{M}$ & 40.38 & 31.98 & 10.79 & 13.83 \\
K562 ВTP2 $25 \mu \mathrm{M}$ & 33.55 & 17.27 & 3.673 & 40.75 \\
\hline
\end{tabular}

\section{Discussion}

Elevated levels of intracellular calcium were detected in the cell lines upon treatment with CCBs. Fluo-8 was used to measure the effect of the CCBs in a concentration dependent manner. With an increase in the $\mathrm{CCBs}$, a rise in mean fluorescence intensity was seen in both the cell lines. ER is the main store for intracellular calcium in a cell [17]. CCBs would block the $\mathrm{Ca}^{2+}$ receptors in the cell and hence it was expected to result in lowering of $\left[\mathrm{Ca}^{2+}\right]_{\mathrm{i}}$. However, as opposed to this, we found the levels of $\left[\mathrm{Ca}^{2+}\right]_{\mathrm{i}}$ to increase. This may be attributed to the fact that we measured the entire $\mathrm{Ca}^{2+}$ present in the cell and the CCBs used were blocking the receptors present on ER [15].

We used Fluo-8, which is a green fluorescence indicator. It uses a fluorescein core to measure the concentration of calcium inside a cell. It determines the total intracellular calcium content of a cell and it is not probable to measure the calcium concentration only inside ER (Lock et al., 2015) [18]. It might be likely that the CCBs were decreasing the calcium content inside the ER but the overall concentration of calcium increased inside the cell.

$\mathrm{Ca}^{2+}$ concentration increase in the cell could be because of release of $\mathrm{Ca}^{2+}$ by $\mathrm{IP}_{3} \mathrm{Rs}$ present on the ER which were not re-up taken by ER since CCBs were blocking the receptors. The increase in $\left[\mathrm{Ca}^{2+}\right]_{i}$ could have also been because of activation of SOCE mechanism. Release of $\mathrm{Ca}^{2+}$ from ER activated the PLC pathway which consequently allowed $\mathrm{Ca}^{2+}$ influx from extracellular spaces by SOCE mechanism [7].

Hotchkiss et al., suggested that $\left[\mathrm{Ca}^{2+}\right]_{\mathrm{i}}$ is a critical regulator between the differentiation and proliferation [19]. To assess the effect of increasing $\left[\mathrm{Ca}^{2+}\right]_{\mathrm{i}}$ on differentiation, we observed the morphology of cells under a microscope. We saw an increase in the number of megakaryocytes with increasing concentration of CCBs $(5 \mu \mathrm{M}$ and $25 \mu \mathrm{M})$. PMA is an identified inducer of differentiation and hence was selected as a positive control [20]. PMA induced differentiation in Marimo cells however, it failed to induce differentiation in K562 cell lines. This might be because PMA requires 48 hours for inducing differentiation and the number of cells killed in the meantime was more than the number of differentiated cells.

Concentration of intracellular calcium largely varies with the stage of the cell. In progenitor cells, calcium concentration is low. There is a slight increase in this concentration when the cell is in megakaryocytic stage.
However, a remarkable increase in the calcium content is noticed just before the differentiation of megakaryocytes into platelets. During differentiation the G-protein coupled receptors initiate calcium influx. Lowering the amount of calcium is associated with inhibition of differentiation [21]. Hence, the increase in calcium with increase in number of megakaryocytes could suggest that a changed intracellular calcium concentration is required for differentiation.

Even though differentiation was seen in cell lines, there was a marked decrease in number of cells with the increasing concentrations of CCBs. This could be reflective of cells undergoing apoptosis because higher concentrations of CCBs $(25 \mu \mathrm{M})$ are toxic for them. Cell cycle analysis was carried out to detect the changes induced by CCBs. A higher number of cells were found in S-phase when the concentration of CCBs were 0-5 $\mu \mathrm{M}$ which rapidly decreased when concentration was increased to $25 \mu \mathrm{M}$. Number of cells present in Sub-G1 phase were also found to increase with increase in concentration of CCBs.

Studies have shown that calcium dependent protein kinases play a major role in numerous cellular processes such as proliferation of $\mathrm{HSCs}$, regulation of cell cycle and apoptosis [22]. Cells that do not proliferate such as HSCs are usually present in G0 phase whereas those present in Sub-G1 phase are indicative of undergoing apoptosis [23].

Apoptotic signalling inside a cell is induced under stress caused by increasing calcium concentration. Mitochondria and ER are two organelles where the earliest and most important events of apoptosis occur. ER-mitochondrial interactions that regulate apoptosis are directed by calcium. Higher concentrations of CCBs causes SERCA block in the ER. This block creates a calcium overload in the mitochondria. Mitochondria release a substantial amount of cytochrome $\mathrm{c}$ in response to the calcium overload. Apoptotic process starts when cytochrome c (a pro-apoptotic factor) activates the caspases and nucleases enzymes [24]. Increase in $\left[\mathrm{Ca}^{2+}\right]_{\mathrm{i}}$ can cause apoptosis by three pathwaysmitochondrial, cytoplasmic and ER stress-related. Cancer cells are known to decrease their $\left[\mathrm{Ca}^{2+}\right]_{\mathrm{i}}$ to evade apoptosis [25]. Since CCBs caused an elevation in $\left[\mathrm{Ca}^{2+}\right]_{\mathrm{i}}$, it may have led to apoptosis of the cells.

Our results thus suggest that using $\mathrm{CCBs}$ increases the $\left[\mathrm{Ca}^{2+}\right]_{\mathrm{i}}$ which leads to differentiation of the cells. However, increase in $\left[\mathrm{Ca}^{2+}\right]_{\mathrm{i}}$ also led to cell death indicating that $\mathrm{CCBs}$ at a higher concentration $(25 \mu \mathrm{M})$ were toxic for the cells and induced apoptosis. 


\section{Conclusion}

In CML, the cells are arrested in megakaryocytic state and are unable to differentiate into platelets. In our experiment, we attempted to induce differentiation in the cell lines K562 and Marimo which were derived from CML patients, using CCBs- fendiline and BTP2. Using the CCBs, we increased the calcium concentration inside the cells. This increased calcium concentration induced differentiation in the two cell lines and it was also seen that it resulted in reduced cell count. We carried a cell cycle analysis and found that though the $\mathrm{CCBs}$ induce differentiation in the CML cell lines, it also causes the cells to undergo apoptosis. We analysed the effect of varying concentrations of $\mathrm{CCBs}$ and found that $\mathrm{CCBs}$ in low concentration $(5 \mu \mathrm{M})$ induced differentiation. However, in higher concentrations $(25 \mu \mathrm{M})$, these CCBs are toxic for the cell lines as they induce apoptosis.

\section{Authorship and Conflict-of-Interest Statements}

1. Aditi Singh-Performed the experiments, collected the data, analysed the data, performed literature review and wrote the paper.

2. Elcim Eroglulari-Performed the experiments and collected the data.

3. Athar Aziz-Designed the experiments and critically reviewed the paper.

We know of no conflicts of interest associated with this publication, and there has been no significant financial support for this work that could have influenced its outcome. We confirm that the manuscript has been read and approved for submission by all the named authors.

\section{References}

[1] Parkash J, \& Asotra K. Calcium wave signaling in cancer cells. Life Sciences. 2010; 87 (19-22): 587-595.

[2] Berridge MJ, Bootman MD \& Roderick HL. Calcium signalling: Dynamics, homeostasis and re-modelling. Nature Reviews Molecular Cell Biology. 2003; 4: 517-529.

[3] Li GR, Sun H, Deng X, Lau CP. Characterization of ionic currents in human mesenchymal stem cells from bone marrow. Stem Cells. 2005; 23: 371-382.

[4] Schwarz DS \& Blower MD. The endoplasmic reticulum: structure, function and response to cellular signaling. Cellular and Molecular Life Sciences. 2016; 73: 79-94.

[5] Jaken S, Yuspa SH. Early signals for keratinocyte differentiation: role of $\mathrm{Ca}^{2+}$-mediated inositol lipid metabolism in normal and neoplastic epidermal cells. Carcinogenesis. 1988; 9 (6): 1033-1038.

[6] Tonelli FM, Santos AK, Gomes DA, et al. Stem cells and calcium signaling. Adv Exp Med Biol. 2012; 740: 891-916.

[7] Tang W, Ziboh VA, Isseroff R, Martinez D. Turnover of inositol phospholipids in cultured murine keratinocytes: possible involvement of inositol triphosphate in cellular differentiation. J. Invest. Dermatol. h1988; 90 (1): 37-43.

[8] Moscat J, Fleming TP, Molloy CJ, Lopez-Barahona M, Aaronson SA. The calcium signal for Balb/MK keratinocyte terminal differentiation induces sustained alterations in phosphoinositide metabolism without detectable protein kinase C activation. J. Biol. Chem. 1989; 264 (19): 11228 11235 .

[9] Sattler R., Tymianski M. Molecular mechanisms of calciumdependent excitotoxicity. J. Mol. Med. 2000; 78: 3-13.

[10] Xu C, Bailly-Maitre B, Reed JC. Endoplasmic reticulum stress: cell life and death decisions. J Clin Invest. 2005; 115 (10): 2656-2664.

[11] Pedriali G, Rimessi A, Sbano L, et al. Regulation of Endoplasmic Reticulum-Mitochondria $\mathrm{Ca}^{2+}$ Transfer and Its Importance for Anti-Cancer Therapies. Front Oncol. 2017; 7: 180.

[12] Hetz C, Chevet E, Oakes SA. Proteostasis control by the unfolded protein response [published correction appears in Nat Cell Biol. 2015 Aug; 17 (8): 1088]. Nat Cell Biol. 2015; 17 (7): 829-838.

[13] Walter P \& Ron D. The unfolded protein response: from stress pathway to homeostatic regulation. Science. 2011; 334: 10811086.

[14] Shore GC, Papa FR, Oakes SA. Signaling cell death from the endoplasmic reticulum stress response. Curr Opin Cell Biol. 2010; 23 (2): 143-149.

[15] Woods N, Trevino J, Coppola D, Chellappan S, Yang S \& Padmanabhan J. Fendiline inhibits proliferation and invasion of pancreatic cancer cells by interfering with ADAM10 activation and $\beta$-catenin signaling. Oncotarget. 2015; 6 (34): 35931-35948.

[16] Núñez L, Valero RA, Senovilla L, Sanz-Blasco S, GarcíaSancho J, Villalobos C. Cell proliferation depends on mitochondrial $\mathrm{Ca} 2+$ uptake: inhibition by salicylate. J Physiol. 2005; 571 (Pt 1): 57-73.

[17] Jan CR, Yu CC \& Huang JK. Dual effect of the antianginal drug fendiline on bladder female transitional carcinoma cells: Mobilization of intracellular $\mathrm{Ca}^{2+}$ and induction of cell death. Pharmacology. 2001; 62: 218-223.

[18] Lock JT, Parker I, \& Smith IF. A comparison of fluorescent $\mathrm{Ca}^{2+}$ indicators for imaging local $\mathrm{Ca}^{2+}$ signals in cultured cells. Cell Calcium. 2015; 58 (6): 638-648.

[19] Hotchkiss A, Feridooni T, Zhang F \& Pasumarthi KB. The effects of calcium channel blockade on proliferation and differentiationof cardiac progenitor cells. Cell Calcium. 2014; 55 (5): 238-251.

[20] Lee CW, Sokoloski JA, Sartorelli AC, \& Handschumacher RE. Induction of the differentiation of HL-60 cells by phorbol 12myristate 13 -acetate activates a $\mathrm{Na}(+)$-dependent uridinetransport system. Involvement of protein kinase $\mathrm{C}$. The Biochemical journal. 1991; 274: 85-90.

[21] Dekker ED, Heemskerk JWM \& Gorter G et al. Cyclic AMP raises intracellular $\mathrm{Ca}^{2+}$ in human megakaryocytes independent of protein kinase A. Arteriosclerosis, Thrombosis and Vascular Biology. 2002; 22: 179-186. 
[22] Mencalha AL, Corrêa S, Abdelhay E. Role of calciumdependent protein kinases in chronic myeloid leukemia: combined effects of PKC and BCR-ABL signaling on cellular alterations during leukemia development. Onco Targets Ther. 2014; 7: 1247-1254.

[23] Hitchcock, I. S., Kaushansky, K. Thrombopoietin from beginning to end. British Journal of Haematology. 2014; 165 (2): 259-68.
[24] Duchen MR. Mitochondria and calcium: from cell signalling to cell death. The Journal of Physiology. 2000; 529 (1): 57-68.

[25] Orrenius S, Zhivotovsky B, Nicotera P. Regulation of cell death: the calcium-apoptosis link. Nature Reviews Molecular Cell Biology. 2003; 4: 552-565. 